\title{
A BIBLIOTECA ESCOLAR E VIRTUAL COMO LÓCUS CIENTÍFICO E INFORMACIONAL
}

\author{
*Maria de Lurdes Teles de Aguiar
}

\begin{abstract}
RESUMO: Este artigo reflete acerca da biblioteca escolar e virtual como instrumentos disponíveis, com a função socioeducativa quando integradas ao cotidiano escolar, sendo uma plataforma de encontro entre professores e alunos na complementação do ensino pedagógico, além de recurso indispensável para a construção de uma cidadania crítica, autônoma e engajada com as demandas da sociedade da informação. Através de uma pesquisa bibliográfica de natureza qualitativa e explicativa demonstra-se aqui que a aplicação de novas práticas vinculadas a um trabalho integrativo entre professor e bibliotecário, no investimento em recursos (acervo, base de dados, internet) para a biblioteca, servirão de suporte no desenvolvimento e geração de informação e conhecimento, repercutindo numa melhoria do desempenho escolar do aluno.
\end{abstract}

\section{Palavras-Chave: Biblioteca Escolar Virtual, Conhecimento, Desempenho Escolar.}

ABSTRACT: This article reflects on the school and virtual library as available instruments, with the socio-educational function when integrated into the school routine, being a platform for teachers and students to complement pedagogical teaching, in addition to being an indispensable resource for building critical citizenship, autonomous and engaged with the demands of the information society. Through a qualitative and explanatory bibliographic research it is demonstrated here that the application of new practices linked to an integrative work between professor and librarian, in the investment in resources (collection, database, internet) for the library, will serve as support in the development and generation of information and knowledge, resulting in an improvement in the student's academic performance.

Keywords: Virtual School Library, Knowledge, School Performance.

RESUMEN: Este artículo reflexiona acerca de la escuela y la biblioteca virtual como instrumentos disponibles, con la función socioeducativa cuando se integra en la rutina escolar, siendo una plataforma de encuentro entre docentes y estudiantes para complementar la enseñanza pedagógica, así como un recurso indispensable para la construcción de una ciudadanía crítica. autónomo y comprometido con las demandas de la sociedad de la información. Através de una investigación bibliográfica de naturaleza cualitativa y explicativa, se demuestra aquí que la aplicación de nuevas prácticas vinculadas a un trabajo integrador entre el maestro y el bibliotecario, en la inversión en recursos (colección, base de datos, internet) para la biblioteca, servirá de apoyo. en el desarrollo y generación de información y conocimiento, lo que resulta en una mejora en el rendimiento académico del estudiante.

Palabras clave: Biblioteca escolar virtual, Conocimiento, Desempeño

* Maria de Lurdes Teles de Aguiar é doutora especialista em Ciências da Educação.

Email para contato: jrmaguiartransporte@yahoo.com.br 


\section{INTRODUÇÃO}

A escola, como disseminadora do conhecimento, é parte fundamental no desenvolvimento do indivíduo. Através do ensino escolar, são transmitidas noções gerais de história e cultura que servirão de base para toda a transformação que o indivíduo poderá sofrer e/ou exercer sobre a sociedade. Com o desenvolvimento científico e tecnológico houve uma mudança na base da sociedade. Vivemos hoje na era da informação e do conhecimento, que se caracteriza pela enorme quantidade de saberes e necessidade de atualização, frente às constantes transformações que se processam rapidamente.

Para que a escola se adapte a estas transformações, é necessária a utilização de todos os recursos disponíveis, e dentre estes, se destaca a biblioteca escolar. Esta possui uma clara função socioeducativa quando integrada ao cotidiano escolar, sendo uma plataforma de encontro entre professores e alunos na complementação do ensino pedagógico.

\section{EDUCAÇÃO, JUVENTUDE, TECNOLOGIA E SABERES}

Vive-se um período de mudanças em todas as esferas sociais do mundo. No Brasil é evidente, de modo particular, mudanças no aspecto educacional que muitas vezes tem alterado a sua dinâmica para dar conta de maneira articulada todas essas transformações.

Na educação para a juventude, atualmente, não é possível deixar de fora a direção que a globalização incute, a sociedade da informação, as exigências de aquisição de habilidades e competências porque são elementos básicos que precisam ser considerados durante as vivências curriculares pelos profissionais da educação. São essas pessoas responsáveis que tem retroalimentado o processo educativo em diferentes épocas e em diferentes culturas.

Nesse sentido, o uso didático de mídias na escola e de maneira especial nas bibliotecas escolares representa processo de modernização do sistema educacional que busca elevar o mesmo tipo de educação a um maior grau de eficácia e eficiência na formação do cidadão que tenha por finalidade a construção de uma sociedade solidária que precisa ser permanentemente reconstruída visando gerações cuja educação esteja voltada para dar valor à solidariedade.

Para que ocorra tudo isso a aplicação de novas práticas vinculadas a um trabalho mais integrativo entre professor e bibliotecário, no investimento em recursos (acervo, base de dados, internet) para a biblioteca, servirão de suporte no desenvolvimento e geração de informação e conhecimento, repercutindo numa melhoria do desempenho escolar do aluno. 


\begin{abstract}
A tecnologia e a competitividade promovem grandes incertezas na vida das pessoas e exigem rápidas transformações na vida dos trabalhadores, de tal maneira, que as gerações mais jovens devem preparar-se para modificar sua profissão várias vezes durante a vida". (FILHO, 2013, p 12).
\end{abstract}

Dessa forma pode-se afirmar que se os professores não estiverem em formação continuada que os orientem na organização de estratégias adequadas para este tipo de ensino, leva-os a situação de inquietação quanto a necessidade desse saber tecnológico para que se atenda com eficiência um ensino aprendizagem para modernidade.

Diante do volume de informações que chega aos educandos, os professores sentem-se preocupados com os efeitos pedagógicos do excesso e da superficialidade da informação, pois é verdadeiro dizer que o educando passa de um site para outro e entra nisso e naquilo sem momentos de reflexão e, portanto para construir conhecimento se faz necessário a intervenção do professor, tarefa que não está sendo nada fácil para os educadores já que a internet, um poderoso banco de dados, virou uma febre que revolucionou a prática da pesquisa em geral.

E nesse caminhar aumenta a responsabilidade do docente em sala de aula que passa a sentir cada vez mais a vontade de aprimorar os conhecimentos e, portanto, sempre abertos a novas informações e novas tecnologias. A escola prepara o educando para o convívio em sociedade. Para que esta possa relacionar-se satisfatoriamente com as questões do seu cotidiano, Antunes (2001) defende que a escola deve propor atividades que levem o aluno a desenvolver certas habilidades, dentre as quais a de ser capaz de debater, deduzir, analisar, interpretar, provar, concluir, conceituar, demonstrar, refletir, criticar, sintetizar, reproduzir, solucionar problemas, pesquisar.

Ao serem estimulados a trabalhar tais habilidades, os educandos precisarão tomar distância do aprendizado centrado na oralidade do professor e do uso quase que exclusivo do livro didático adotado para as disciplinas, e aproximarem-se cada vez mais da biblioteca da escola. Isto promoverá uma mudança no ato de ensinar e de aprender, fazendo com que se estabeleça um trabalho mais cooperativo e participativo entre bibliotecário e professor, resultando numa maior aproximação do aluno com a biblioteca escolar e ao acesso às informações ali disponibilizadas.

É válido salientar a interpretação feita do que diz Moran (2005) em seu texto "Desafios da Internet para o Professor", que ensinar na e com a internet atinge resultados significativos quando está integrada em um contexto estrutural de mudança do ensino-aprendizagem, onde professores e alunos vivenciam processos de comunicação abertos, de participação interpessoal e grupal efetivos. Caso contrário, a internet será uma tecnologia a mais, que reforçará as formas tradicionais de ensino. 
A internet não modifica sozinha, o processo de ensinar e aprender, mas depende essa mudança da atitude básica pessoal diante da vida, do mundo, de si mesmo e do outro e das atitudes fundamentais das instituições escolares. A palavra-chave é integrar: integrar a internet com as outras tecnologias na educação - vídeo, televisão, jornal, computador, celular. Integrar o mais avançado com as técnicas convencionais, integrar o humano e o tecnológico, dentro de uma visão pedagógica nova, criativa, aberta.

\section{1 - BIBLIOTECA ESCOLAR: BERÇO DO EXERCÍCIO DO TRABALHO COM A INFORMAÇÃO E A COMUNICAÇÃO.}

Atualmente o uso e a transferência de informação vêm sofrendo uma série de mudanças nas últimas décadas, devido à era do conhecimento. A gestão da informação vem reforçando esse período e dando o devido suporte para administrar, organizar e compartilhar a informação e o conhecimento.

O uso estratégico da informação é a alavanca para estimular e gerar conhecimento dentro de uma organização. Sem informação não há possibilidade de se estabelecer alternativas na tomada de decisão, não há como gerar conhecimento. Se a informação é um bem tão precioso para qualquer tomada de decisão e para a sobrevivência de uma empresa, por que se investe tão pouco em educação básica?

Por que se fala tanto em gestão da informação e do conhecimento e pouco se investe em escolas e em bibliotecas? Por que não investir mais nas mesmas? Campello (2003) enfatiza: “Trabalhando em conjunto, professores e bibliotecários planejarão situações de aprendizagem que desafiem e motivem os alunos, acompanhando seus progressos, orientando-os e guiandoos no desenvolvimento de informações cada vez mais sofisticadas". (CAMPELLO, 2003, p. 11)

Percebe-se que, dessa maneira, a biblioteca estará realmente assegurando sua finalidade, mostrando possibilidades valiosas no desenvolvimento de suas atividades, aproximando professor e bibliotecário na execução delas, e estimulando no aluno a busca e leitura da informação.

Sabe-se que, na ânsia de incentivar à leitura, o papel do bibliotecário e dos professores não são tão satisfatórios, pois esquecem que a leitura tem a sua efetiva importância quando o aluno consegue ser proativo, criando, reproduzindo, socializando no ambiente em que vive e exteriorizando sua experiência de vida com a informação recebida. 
Carvalho (2003) convida a repensar o papel da biblioteca, no que diz respeito à promoção do incentivo à leitura e na mediação do processo ensino-aprendizagem que tem implicações porquê de acordo com Ramos (2012) ultrapassam de longe os muros da escola ou de uma sala de aula favorecendo grandes mudanças neste período que está sendo chamado de revolucionário e assemelha-se a diversos momentos da história da nossa civilização como a revolução industrial que também apresentou problemas com relação aos diferentes tipos de profissões e trabalho que mesmo surgindo o desemprego, a falta de qualificação profissional, principalmente, aumenta.

É importante afirmar que se fazem necessárias reflexões e como consequência novas ações para as pessoas envolvidas com a tarefa educativa, na tentativa de buscar caminhos que ampliem a qualidade do ensino e da aprendizagem cuja finalidade é a formação de sociedades democráticas e participativas. A TIC (Tecnologia da Informação e Comunicação) abre muitas possibilidades no âmbito da existência de uma tecnodemocracia que é definido como uma nova formação política em que os meios técnicos viabilizam o desenvolvimento de comunidades inteligentes capazes de se autogerir (RAMOS, 2012).

Neste cenário coloca-se Hillesheim e Fachin (1999), que enfatizam os objetivos da biblioteca escolar: ampliar conhecimento; oferecer ambiente que favoreça a formação e o desenvolvimento do hábito de leitura e de pesquisa; oferecer ao professor subsídios para a implementação de seu trabalho; estimular nos alunos o hábito de frequência a outras bibliotecas na busca de informações e/ou lazer, cooperar com o currículo escolar, no atendimento às necessidades da comunidade escolar, proporcionar aos usuários materiais diversos e serviços bibliotecários adequados ao aperfeiçoamento e desenvolvimento individual; orientar e estimular os alunos em todos os aspectos da leitura; participar dos programas e atividades da escola; propor atividades culturais estimulando o uso na busca de lazer e de pesquisa, integrando a comunidade escolar; orientar o uso do livro, visando à pesquisa e à educação individual.

Mas, para alcançar tais objetivos a biblioteca deve ser tema de discussão na escola, devendo ficar explícito o compromisso que cada categoria, que integra a comunidade escolar, deve ter para com este espaço. Neste sentido, as bibliotecas assumem papel fundamental ao possibilitar as pessoas o acesso à leitura, através do seu acervo e, mais precisamente, por meio daqueles que são a mais fiel tradução do conhecimento disponibilizado no mundo: os livros. Tamanha é a responsabilidade daqueles que a administram, pois pequenas ações dentro das bibliotecas podem constituir-se em eventos significativos na promoção da leitura. 
Novas tecnologias surgem diariamente e as pessoas não se dão conta de que ações pedagógicas são mais importantes que meras organizações de atividades. Bibliotecas e livros são memória e construção do mundo, faltando cogitar mais explicitamente sobre a leitura, elemento fundamental na ação com os acervos. Nossos leitores possuem necessidades que outrora não existiam, seja no caso de informação, como também no seu suporte. Em virtude disso, também as bibliotecas têm que se adequarem a esta nova demanda, oferecendo serviços e atividades que promovam o prazer de ler nos leitores.

\section{2 - PRESSUPOSTOS PARA O ENTENDIMENTO DA BIBLIOTECA VIRTUAL PARA A PESQUISA CIENTÍFICA}

Considerando diferentes visões acerca do objeto que agora se delineia, a biblioteca virtual conforme (BORGMAN, 2000, SARACEVIC, 2001, E DALBELLO, 2001) propõe-se um conceito que represente um conjunto de ideias sobre este tipo de instituição voltada para a pesquisa científica. Neste sentido, formula-se a seguinte definição: "Biblioteca Virtual é um serviço on-line de informação especializada, criado para atender as novas exigências da pesquisa acadêmica, sobretudo no que diz respeito à agilidade para a obtenção da informação e para a comunicação entre pares”. (BORGMAN, 2000, p.125).

Decorre de um trabalho intelectual, o que pressupõe a participação de atores humanos para a sua estruturação, funcionando como um filtro para excluir informação irrelevante e, ao contrário, tornar disponíveis itens úteis e de alta qualidade. Assim, seu escopo exige o estabelecimento de uma política de seleção que considera um conjunto de atributos para a coleta e escolha das fontes de informação que compõem o seu conteúdo, formado por dados, que tanto descrevem os dados quanto são elos para outros dados.

Tal conjunto resulta de uma considerável ampliação do material impresso para uma grande variedade de recursos desmaterializados que:

a) consistem em representações digitais de objetos criados ou adaptados para este ambiente;

b) são distribuídos em muitos servidores e acessados livremente ou mediante compra ou licença, valendo considerar que a economia do acesso aos recursos é mais importante que a economia da propriedade deles.

A biblioteca virtual conforme Saracevic e Dalbello (2001) distinguem-se das ferramentas de busca da internet pela consistência dos resultados que o usuário final recebe em sua busca por informação, embora o uso intensivo de ferramentas eletrônicas seja uma 
exigência para a localização, manutenção e monitoramento da informação que disponibiliza. Pelo fato de constituir-se na internet, distingue-se, igualmente, das bibliotecas, dos centros de documentação e de outros lugares físicos que organizam, armazenam e disseminam informação, que, no entanto, já se pode chamar de "híbridos": não os substitui, embora deva complementálos.

Tem um alcance amplo e diferenciado, por também prover dispositivos de comunicação e diversos serviços, fortemente marcados pelas especificidades da tecnologia digital em rede eletrônica, que permitem que usuários de uma ou de várias comunidades interajam, mesmo que dispersos em diferentes lugares. A biblioteca virtual passa a estar, assim, cada vez mais entranhada nas atividades sociais dos pesquisadores, o que revela sua força potencial para o incremento da pesquisa acadêmica. (SARACEVIC \& DALBELLO, 2001).

Assim, a biblioteca virtual, examinada neste estudo como um "objeto científicotécnico e informacional" (SANTOS, 1997) é um desses novos mecanismos a integrar a infraestrutura de informação necessária ao desenvolvimento da pesquisa, pois esta, como se sabe, não pode prescindir de um aparato complexo para desenvolver-se.

O ambiente tecnológico que abriga e dissemina a informação, passa por rápidas e intensas transformações, conforme estes "tempos acelerados" em que se vive. Cabe lembrar que o novo milênio herda um enorme e veloz crescimento da comunidade científica e da informação por ela produzida, bem como uma grande expansão do emprego de métodos e meios eletrônicos ao longo de toda a cadeia de construção do saber científico, que segundo Meadows (2008) em seu livro "A Comunicação Científica", embora enfatize a experiência dos países centrais, não deixa de observar a situação dos países periféricos em relação a tais questões.

A eficiência de uma biblioteca deve ser medida pela rapidez com que é possível localizar um livro, e desta forma, entende-se que a organização da informação nas bibliotecas se faz, exatamente para atender a esse anseio, ou seja, para poupar o tempo do leitor. A organização da informação será aqui entendida conforme Fujita (2003) como processo relacionado ao tratamento intelectual da informação que inclui a análise descritiva e a análise temática da informação, através das operações de catalogação, classificação.

A catalogação em bibliotecas escolares é efetuada pelos mesmos motivos das demais bibliotecas: recuperar informações. No entanto, há especificidades da realidade das bibliotecas escolares (brasileiras) que precisam ser levadas em conta: a primeira é que os catalogadores nem sempre são profissionais habilitados para tal atividade; a segunda, que é consequência da primeira, é o desconhecimento de que tal atividade deve ser feita em função do seu público, neste caso pouco especializado; a terceira pela falta de recursos financeiros e tecnológicos para o desenvolvimento do trabalho.

(PIMENTEL, 2007). 
Apesar desta realidade, a catalogação do acervo existente nas bibliotecas escolares pode e deve ser feita, e neste sentido, é vital escolher um sistema de catálogo para a biblioteca escolar, que permita a classificação e catalogação dos recursos informativos de acordo com padrões bibliográficos aceitos nacional e internacionalmente, pois facilita a sua inclusão em grandes redes de informação.

Também recomenda que as bibliotecas escolares de comunidades locais façam parte de um catálogo coletivo, visto que tal colaboração poderá aprimorar a eficiência e a qualidade do processamento técnico dos livros. Pimentel (2007) sugere que nas bibliotecas escolares existam um catálogo de autor, título, assunto e um catálogo dicionário. Para a autora, estes catálogos podem estar dispostos em diferentes formas, tais como livros, folhas soltas ou fichas catalográficas, pois a escolha do melhor tipo de catálogo dependerá dos recursos disponíveis em cada biblioteca, do tamanho do seu acervo e das características dos usuários que deverão utilizá-lo.

Partindo do princípio descrito por Vianna (2008, p.46), no qual afirma que "se a biblioteca escolar for organizada de acordo com um sistema que seja utilizado pela maioria das bibliotecas, o estudante terá mais segurança e estímulo para explorar os acervos de outras bibliotecas". Entende-se que a escolha de um sistema de classificação neste tipo de biblioteca determinará não só o uso de seu acervo, mas a formação intelectual de seus usuários.

Nesta mesma perspectiva, Hoffman e Pereira (2006) também afirmam que a biblioteca escolar deve ter o compromisso de educar seus usuários no uso e manuseio adequado dos documentos que compõem o seu acervo, tornando-os aptos a utilizarem bibliotecas em quaisquer outras instituições por eles frequentadas. Por esse motivo, as autoras, igualmente defendem o uso de princípios básicos de organização utilizados em nível nacional e internacional nas bibliotecas escolares, como forma de proporcionar aos seus usuários a compreensão dos sistemas utilizados para o controle dos acervos, bem como das regras de funcionamento em outras instituições.

Identificada como parte do processo de transformação e qualificação da escola, a biblioteca assume nesse modelo escolar um papel de importância capital no processo de formação dos estudantes e deve estar integrada ao conjunto de ações das práticas pedagógicas.

Ao se integrar ao PPP (Projeto Político-pedagógico) da escola, a biblioteca escolar não apenas insere seu trabalho na promoção da leitura, mas atua de maneira eficiente como elemento de apoio na aquisição e construção do conhecimento, seja no suporte para a realização das pesquisas escolares, seja na melhoria da capacidade de escrita, da argumentação, da 
ampliação e diversificação do vocabulário e de outras habilidades e competências essenciais à formação humana e acadêmica da juventude.

"Como ambiente de formação, a biblioteca deve ser fonte de experiência e conhecimento, exercício da cidadania e formação para toda vida da comunidade escolar: estudantes, professores, funcionários, famílias". (VIANNA, 2008)

A biblioteca está mudando rapidamente, da dependência de uma coleção delimitada, para o acesso direto a uma vasta quantidade de informação em rede na internet e para uma variedade de bibliotecas digitais. Sendo assim, a pesquisa escolar se constrói mediante as atividades pedagógicas que visam atender e desvendar determinadas áreas do conhecimento, constituindo-se, portanto, em uma das atividades mais relevantes do processo de ensinoaprendizagem escolar. Ressalta-se que Ellwein (2006) já apontava a relevância desta atividade pedagógica como excelente recurso para a aprendizagem. A pesquisa escolar é relevante, não somente no sentido de proporcionar aos alunos o maior contato com a biblioteca e a informação, mas também por possibilitar a construção de novos conhecimentos.

Segundo Faqueti e Rados (2002, p. 3), a pesquisa escolar é uma ação em que "os sujeitos envolvidos buscam respostas, reorganizam seus conhecimentos já existentes dandolhes um novo arranjo e agregando-lhes valores distintos de caráter inusitado".

Nesse contexto, Ellwein (2006) ressalta que a orientação a ser realizada por bibliotecários no desenvolvimento da pesquisa escolar, assim como a disponibilização de um acervo que auxilie na consecução desta atividade, são considerados requisitos essenciais ao êxito da pesquisa escolar como recurso de aprendizagem.

Os autores supracitados apontam para diversos aspectos no que se refere aos meios utilizados pelos bibliotecários para auxiliar o aluno na pesquisa escolar e à participação deles no desenvolvimento de tais atividades. Considera-se também que o professor pode oferecer suporte às atividades de pesquisado educando por meio da integração com a biblioteca e seus profissionais.

Pode-se concordar com Antunes (2001) e os Parâmetros Curriculares Nacionais PCNs, (1997) que apontam a escola como responsável em desenvolver habilidades para que os alunos possam relacionar-se satisfatoriamente com as questões impostas pela sociedade. E isto será possível quando a biblioteca escolar for discutida e entendida, por educadores, bibliotecários que estão em cargos de decisão, nas esferas federal, estadual e municipal, e pelos demais segmentos que integram a sociedade. 


\section{CONSIDERAÇÕES FINAIS}

Entende-se aqui que a biblioteca não é um espaço para servir ao professor e à sala de aula para o desenvolvimento de atividades recreativas nem para o exercício de tarefas didatizantes. Tampouco se trata de um templo fechado, restrito ao silêncio, com as obras guardadas e conservadas, mas também não é um parque de diversões, onde o estímulo visual torna-se prioritário para a promoção da leitura.

É sim um espaço onde o livro físico e o acesso virtual devem ser possibilitados e incentivados promovendo a compreensão desse acesso virtual a textos para o mudo atual, onde o livro didático deve ser utilizado como ferramenta importante para o processo acadêmico, porém se faz necessário construir familiaridade com as diferentes mídias disponíveis, cuidando de verificar as fontes confiáveis da informação;

É imprescindível aqui demonstrar o potencial dos novos meios eletrônicos para o incremento da pesquisa científica, com a divulgação das possibilidades oferecidas por esses novos meios, bem como a busca pela solução dos problemas apontados, fazendo vislumbrar oportunidades para a renovação do trabalho dos profissionais de informação, tanto dos envolvidos com as bibliotecas físicas (que já se tornam híbridas) quanto com as bibliotecas virtuais.

Reconhecer que a biblioteca virtual se caracteriza como um instrumento imprescindível para integrar a infraestrutura básica da ciência: apoia o desenvolvimento científico, na medida em que responde às emergentes mudanças que se processam em torno da informação e em função da evolução dos mecanismos de comunicação que pode e deve abrigar, os quais superam as dificuldades relacionadas às contingências impostas pelo tempo e pela distância. E assim compreender que a leitura de cada aluno, de cada, educador, de cada funcionário que frequenta a biblioteca deve ser respeitada em suas especificidades. Esse é o paradigma da leitura autônoma e cidadã.

\section{REFERÊNCIAS}

AGUIAR, Vera Teixeira de; MARTHA, Alice Áurea Penteado (Orgs.). Territórios da leitura: da literatura aos leitores. São Paulo: Cultura Acadêmica, 2006.

ANTUNES, C. Trabalhando habilidades: construindo ideias. São Paulo: Scipione, 2001. BRASIL. Parâmetros Curriculares Nacionais. Brasília: MEC, 1997. v. 2 
BORGMAN, C. L. Documentários de Jornal. v. 56, n.4, jul. 2000.

CAMPELLO, B. A biblioteca escolar: temas para uma prática pedagógica.2ed. Belo Horizonte: Autêntica, 2003.

CARVALHO, M. C. Escola, biblioteca e leitura. In: CAMPELLO, B. A biblioteca escolar: temas para uma prática pedagógica. 2. ed. Belo Horizonte: Autêntica, 2003.

ELLWEIN, S. A. F. Pesquisa escolar e o enfadonho exercício de cópia: como separar o trigo do joio? In: SILVA, R. J.; BORTOLIN, S. (Org.). Fazeres cotidianos na biblioteca escolar. São Paulo.

FAQUETTI, Marouva Fallgatter; RADOS, Gregório Varvakis. Dinâmica evolutiva da pesquisa escolar: proposta de um modelo. In: SEMINÁRIO NACIONAL DE BIBLIOTECAS UNIVERSITÁRIAS, 16., 2010. Rio de Janeiro. Anais... Rio de Janeiro: UFRJ, 2010. p. 1-14. Disponível em: Acesso em: 10 fev. 2017.

FILHO, V. H.O. As Novas Tecnologias e a Mediação do Processo Ensino-Aprendizagem na Escola. Artigo publicado em 2012.

FUJITA, Mariângela Spotti. Lopes A análise documentária no tratamento da informação: as operações e os aspectos conceituais interdisciplinares. Marília: Departamento de Ciência da Informação, FFC/UNESP, 2003b. $15 f$

HILLESHEIM, Araci Isaltina de Andrade; FACHIN, Gleisy Regina Bories. Conhecer e ser uma biblioteca escolar no ensino-aprendizagem. Revista ACB, Florianópolis, v. 4, n. 4, p. 64-79, 1999.

MORAN, J. M. Como utilizar a Internet na Educação. Artigo publicado na Revista Ciência da Informação, vol. 26, n.2, 2005.

PEREIRA, A. K. Biblioteca na escola. Brasília: Ministério da Educação, Secretaria de Educação Básica, 2006. 57pp.

PIMENTEL, G.; BERNARDES, L.; SANTANA, M. Biblioteca escolar. Disponível em:. Acesso em: 18 jun. 2016.

RAMOS, E. Introdução a Educação Digital. Guia do Cursista, MEC/PROINFO, Brasília 2013.

SANTOS, C. M. C. O livro didático do ensino fundamental: As escolhas do professor. Dissertação (Mestrado em Educação). Universidade Federal do Paraná, 1997.

SERACEVIC, T., DALBELlO, M. Metodologias para bibliotecas digitais. São Paulo: Cortez Editora, 2001.

VIANNA, M. M.; CAMPELLO, B.; MOURA, V. H. V. Biblioteca escolar: espaço de ação pedagógica. Belo Horizonte: EB/UFMG, 1999. 
